The Least Worst Option: User experiences of antipsychotic medication and lack of involvement in medication decisions in a UK community sample

Authors:

Nicola Morant 1

Kiran Azam²

Sonia Johnson ${ }^{1}$

Joanna Moncrieff ${ }^{1,2 *}$

${ }^{1}$ Division of Psychiatry, University College London, Maple house 149, Tottenham Court Road, London W1T 7NF, United Kingdom, Tel 02076799424.

${ }^{2}$ North East London NHS Foundation Trust, Research \& Development department, Goodmayes Hospital, Barley Lane, Goodmayes, Essex, United Kingdom.

* corresponding author j.moncrieff@ucl.ac.uk, Tel 03005551201X65714 


\title{
The Least Worst Option: User experiences of antipsychotic medication and lack of involvement in medication decisions in a UK community sample
}

\begin{abstract}
Background: Treatment decision-making that fully involves service users is an aim across medicine, including mental health.
\end{abstract}

Aims: To explore service users' experiences of taking antipsychotic medication for psychotic disorders, and their perceptions of decision-making about this.

Method: Semi-structured interviews with 20 users of community mental health services, conducted by service user researchers and analysed using thematic analysis.

Results: Antipsychotic medication was perceived to have beneficial effects on symptoms and relapse risk, but adverse effects were prominent, including a global state of lethargy and demotivation. Weighing these up, the majority viewed antipsychotics as the least worst option. Participants were split between positions of 'willing acceptance', 'resigned acceptance' and 'non-acceptance' of taking antipsychotics. Many felt their choices about medication were limited, due to the nature of their illness or pressure from other people. They commonly experienced their prescribing psychiatrist as not sufficiently acknowledging the negative impacts of medication on life quality, and physical health concerns, and described feeling powerless to influence decisions about their medication.

Conclusions: The study highlights the complexity of agendas surrounding antipsychotic medication, including the pervasive influence of coercive processes, and the challenges of implementing collaborative decision-making for people with serious mental health problems. 
Declaration of Interest: the work was funded by the National Institute of Health Research. There are no conflicts of interest.

\section{Keywords:}

Antipsychotics; schizophrenia; subjective experience of antipsychotics; decision making; qualitative research. 


\section{Introduction}

Antipsychotic medication is the principal form of treatment for people with schizophrenia and long-term psychotic conditions. Despite their effectiveness in reducing acute symptoms and risk of relapse (Leucht et al., 2008, Leucht et al., 2012), antipsychotics produce an array of adverse effects and may contribute to reduced subjective life quality and functioning (Bebbington et al., 2009, Hofer et al., 2004, Wunderink et al., 2013, Wykes et al., 2017).

Research on experiences of medicine-taking highlights how people evaluate medication use according to personal goals, values and circumstances, weighing up factors including symptom reduction, adverse effects, stigma and inconvenience (Donovan \& Blake, 1992, Karp, 1993, Pound et al., 2005, Venn \& Arber, 2012, Zhou, 2016). A synthesis of qualitative studies identified several distinctive stances (Pound et al., 2005). People classified as 'active accepters' evaluated medicine use, and actively accepted doctor's recommendations; 'active modifiers' evaluated and adapted prescribed regimes; 'passive accepters' accepted prescribed medicine without question; 'rejecters' rejected medication altogether.

In mental health care the meaning of medication is rendered more complex by debates about the nature of mental health problems, the presence of coercion and occasional impaired or fluctuating capacity (Norvoll \& Pedersen, 2016, Szasz, 1970). Evaluating the impact of antipsychotic treatment is complex therefore, and users, clinicians and family members may have different priorities (Angermeyer et al., 2001, Finn et al., 1990, Rettenbacher et al., 2004).

These considerations may explain why shared-decision making in mental health care lags behind other areas (Morant et al., 2015). Although recommended for people with serious mental disorders (National Institute for Health and Care Excellence, 2014, The Schizophrenia Commission, 2012), mental health service users commonly report feeling they lack choice 
and are uninvolved in treatment decisions (Goss et al., 2008, Hogman \& Sandamas, 2000, Olofinjana \& Taylor, 2005, Rogers et al., 1998, Usher, 2001). The current study aimed to explore experiences of taking antipsychotic medication and how decisions about medication are made.

\section{Methods}

\section{Sample}

Participants were recruited from community mental health services in north east London. Inclusion criteria were having a psychotic condition, and taking, or having taken antipsychotic medication in the last three months. Participants were initially approached by a member of the clinical teams, who were provided with the inclusion criteria. Patients were purposively sampled according to whether they took medication orally or by depot injection, duration of treatment and illness, positive or negative views of medication, and gender. Characteristics were reviewed monthly during recruitment to ensure a range of medication experiences were captured. Ethical approval was obtained from West London REC 1 (Reference: 11/LO/0225).

\section{Data collection}

A semi-structured interview schedule was developed in collaboration with an established mental health service users group (South Essex Service User Research Group; SE-SURG) over the course of three meetings. The focus and wording of questions were informed by existing literature and issues that group members considered relevant, expressed in their own terms. The final schedule covered: Current medication and medication history; reasons for 
taking medication; experienced effects of medication (positive and negative); views on longterm use; deviations from prescribed regimes; and discussions with health practitioners about medication, including how decisions are made.

In order to enhance rapport and openness, interviews were conducted by five service user researchers from SE-SURG, with one interview conducted by the study researcher. Most interviewers had prior experience of qualitative interviewing and all received additional training. Interviewers disclosed their status as mental health service users at the beginning of the interview. Participants were reminded about confidentiality, especially at sensitive points (such as when discussing self-medication strategies and relations with service providers). Data was collected in a single interview, conducted in participants' homes or out-patient clinics and typically lasted for 45 minutes. Interviews were audio-recorded and transcribed.

\section{Data analysis}

Data were analysed using thematic analysis within NVivo software (Braun \& Clark, 2006). The analytic strategy combined inductive and deductive approaches throughout, allowing exploration of initial research questions (such as the effects of taking medication), as well as issues that characterised participants' own experiences. Thus some themes (e.g. fear of relapse) were not asked about explicitly, and emerged at several points in the interview. A collaborative approach to theme development was adopted, involving independent readings of sample transcripts and comparisons of interpretations by NM, KA and JM. We were critically aware of our existing preconceptions as academics, researchers and clinicians, and integrated service users' perspectives into early stages of the analytic process: Service user interviewers were invited to review, discuss and modify an initial set of emerging themes in a half-day meeting, with prior preparation. Issues they identified here, and in their interviewing 
experiences were integrated into analysis and explored further. These collective processes enhanced validity by encouraging high levels of reflexivity (Barry et al., 1999), and ensuring that the perspectives of service users informed the analysis (Gillard et al., 2012).

\section{$\underline{\text { Results }}$}

\section{Sample characteristics and medication histories}

Twenty people (13 male, 7 female) were interviewed. Demographic and medication use characteristics are shown in Table 1. All participants had a diagnosis of schizophrenia or schizoaffective disorder according to medical records. There was a wide range of selfreported duration of antipsychotic use, with half the sample reporting more than 10 years of antipsychotic use. Two participants were subject to Community Treatment Orders (CTOs) (participants 07 and 09), a legal measure applying within England and Wales requiring acceptance of treatment conditions, commonly including antipsychotic medication. Twelve participants received some or all of their medication via long-acting depot injection.

\section{Effects of antipsychotic medication}

All but one participant reported at least one positive effect of being on antipsychotic medication. Medication was valued for reducing psychotic symptoms, and facilitating a "normal" life that included work, independent living or socializing with family or friends.

"It keeps the symptoms of schizophrenia to a minimum. And gives me a relatively normal life." (Int18) 
“With Abilify [aripirazole] it's really helped. My mom noticed it first, she said it's like oh we've got the old [name] back, before I got ill, you know, which was a lovely thing, and it was true because I was more acting normal, you know. ... I talk to them [family and friends] more, umm, looking after myself better, eating properly, sleeping and generally getting on with my life." (Int16)

A second commonly cited positive effect of medication was relapse prevention. The desire to not to be acutely unwell again was often strong, and appeared to be motivated partly by fear associated with previous negative experiences of coercion and hospitalization.

"[I take medication] in order to prevent, I've had three sections ${ }^{1}$ in England, one in Australia, previously I've always refused to take the antipsychotic medications, partly because I didn't think I needed them and because of the major side effects that I receive. This time the message has finally got through to me, take them and hopefully I won't get sectioned again...because I don't want to go to the hospital again." (Int15)

Simultaneously, negative experiences of medication were reported by all but two respondents. Several described a global state characterized by tiredness, lethargy, demotivation and personality change, along with various physical complaints. These effects impacted negatively on respondents' lives, preventing them from doing things they wanted to do, such as daily tasks, exercise or socialising.

“I've developed social phobia, I've developed diabetes, I've got blood pressure, I ain't got many friends ... it [medication] just ruins your life... it makes me lazy. It makes me groggy, first week it's just like your body's hurting, you've got no

\footnotetext{
${ }^{1}$ Compulsory admissions to hospital under a section of the Mental Health Act of England and Wales.
} 
motivation, makes you lazy...It's just the pain in the body. If you go to the gym the next day it's double the pain, your legs are hurting from the medicine... The medicine hammers you more than the spirits in my life" (Int12)

For one participant the slowing effect of the medication may have been mirrored in long pauses in his account:

"[The medication] makes me put on weight actually, $(7)^{2}$ reduces my motivation (10), changes other people's attitudes towards me for the worse (4), makes me feel depressed (10), sometimes I'm restless sometimes, (4), has a negative effect on my day to day living....Uh, umm, (4) it's very, it sort of relaxes me. It slows me, slows me down, it does, it just, it seems to do something mentally that's, that's quite sort of (5). Think it slows down the thought processes and stuff, I'm not sure what it does. Well just that it makes me so physically disabled, so it reduces my ability to function normally.” (Int04)

\section{Levels of acceptance of antipsychotic medication: The least worst option?}

It was evident from accounts that weighing up the positive and negative effects of medication was a central and complex feature of respondents' lives. For over two thirds of our sample, this resulted in a general acceptance of taking antipsychotics, in which medication was viewed as 'the least worst' option. For half these people, whom we term 'willing accepters,' the positives effects of medication broadly outweighed negative effects. Only one person in this group took medication by depot injection.

\footnotetext{
${ }^{2}$ Lengths of pause in seconds.
} 
"The side effects aren't sort of unbearable, I'm able to live with them so it doesn't have too bad ... they seem to have been keeping me well for about 12 years. So I think they do keep the symptoms of schizophrenia low. So generally speaking, I am glad to be taking it, it seems to be working." (Int18)

The other half of this 'accepters' group, who could be described as 'resigned accepters' showed more resignation. Many of these people described considerable negative effects that impacted more significantly on life quality. Some in this group described having travelled a difficult 'journey of acceptance' to arrive at their current position.

"It's a balancing act and I have to keep reminding myself with those list of negatives, you don't want to go back to hospital and you don't want to be unwell for 12 months, so, so it is a balancing act. Some days I do feel as if the negatives are too much. Umm, but I've been taking it religiously every day." (Int15)

The other third of respondents could be viewed as 'non-accepters.' They felt they had little choice over taking medication and many did not accept professional views that they were ill or needed medication. They rated negative effects as outweighing positive effects, and often described feeling 'forced' to take medication (see next section). All of these people took some or all of their antipsychotic medication by depot injection, and the two people subject to CTOs were in this group.

A common theme across the whole sample, even among those who were generally positive about medication currently, was almost universal concern, regarding taking medication on a long-term basis. Concerns centered around the long-term effects of antipsychotics on physical health, with most people saying they would like to reduce or come off their medication eventually. 
"I'm worried about the fact that I might develop diabetes because I'm putting on so much weigh all the time, its constant, umm,... I'm worried about those things.... It's going to have a long term detrimental impact." (Int07)

\section{Limitations to choice and control}

A sense of limited choice and control over taking antipsychotic medication was common across interviews, related by respondents to the nature of psychotic illnesses, pressures from other people, or taking medication by depot injection. For many respondents, limited choice arose from the persistent or recurrent nature of their mental health problems. Most of these people were in our category of 'resigned accepters', and had adopted an internalized or selfimposed sense of reduced choice, often related to fears of relapse or returning symptoms.

"I'd feel scared about stopping the medication because I'm scared of the hallucinations and the voices coming back, because they were quite scary for me. So I feel like I have to [take medication], but I don't feel like anyone particular is pressurizing me into doing it" (Int14)

Half of respondents described influence or pressure from other people (mental health practitioners and / or family members) as either the main reason or one of several reasons for taking medication. This included all the people in the 'non-accepters' group (many of whom cited external pressure as the only reason they took medication), some 'resigned accepters', and people who took medication both orally and by depot injection. Several of these people said they didn't want to take medication either because they felt they didn't need it, or because of negative side effects. Perhaps not surprisingly, the two respondents subject to CTOs describe this in terms of being 'forced' or 'controlled' by service providers. For some respondents, coercive past experiences shaped their sense of constrained choice: 
“I don't think I need medication. I have no option at the moment...I wasn't taking my medication at one time, I refused to take it. I was put in hospital...if I didn't go in voluntary, I would have been sectioned....I don't think I'm ill....I don't think I need it." (Int06)

Others described less coercive forms of pressure from family members or health practitioners:

[I take medication] "because people want me to...Yea, otherwise you get pressured by people and I don't want to upset my family or anything like that.” (Int12)

Receiving long-acting depot injections was associated with a greater sense of being forced or pressured to take medication, and some participants contrasted this with greater possibilities for exercising choice and control offered by taking medication orally:

"I've had this illness all my life, I can't control it at all but I can control how much medication [the tablets] I have, that's one bit of control I've got." (Int17; on depot and tablets)

Underlining this sense of limited choice and control, accounts of self-modification of medication regimes were rare, despite respondents being interviewed by a service user who provided reassurance about confidentiality and acknowledgement that these practices are common. Five participants admitted to relatively minor modifications of medication regimes, such as increasing the dose to manage agitation, lowering the dose and missing occasional doses due to social plans or the need to be active:

"I did make a conscious effort a couple of times not to take it because I knew I had quite a lot going on the next day, and I needed the energy...I knew I was going out during the day and I didn't want to be tired." (Int15) 


\section{Discussing medication with professionals: Passive involvement and lack of trust}

Despite concerns about current adverse effects and long-term use of medication, and preferences for more choice, a sense of passivity characterised many accounts of discussions with prescribers. Several respondents explicitly said they had never raised concerns about long-term use and adverse effects, and their long-term preferences did not feature in discussions with prescribers. There was a strong awareness of power inequalities, with many participants feeling their concerns were not properly acknowledged or given time for discussion, and they were not able to shape decisions about their treatment.

For some this was a source of frustration and powerlessness. Others conveyed a more passive stance that it 'wasn't their place' to raise concerns or appear to challenge the doctor's agenda. Participants described two related issues they felt powerless to address. Firstly, many expressed a desire to lower or stop their antipsychotic medication, but felt their psychiatrist would not agree to this.

"I'd like to come off it to be truthful. Come off the whole lot. See how Ifeel not on it, but I don't think they will ever let me. ... When I see my psychiatrist he's only ever asked me how I'm feeling. We never actually discuss the medication or if we do, I have to make a point of it because of side effects and things like that, but apart from that it's not really discussed." [40 seconds more talk] "Sometimes I don't think that they listen, it's just carry on taking medication, see you in 6 months' time and carry on what you are doing." (Int17)

"Yea, we always discuss it, yea. See I leave it up to her, you see. I never say to her about lowering it, I always leave it up to her and that's about all. We, she asks me 
questions, about how I been coming on...no I never say about coming off them to her...Because I know they won't do it. They won't do it, see." (Int02)

Secondly, participants reported difficulties in communicating their concerns about adverse effects of antipsychotics, including poor life quality associated with these. They felt that professionals did not pay enough attention to the physical effects of antipsychotics and often prioritized reducing psychotic symptoms over minimizing negative effects.

"You have to adjust your mind, as I said, like it's getting to me. It got to me like I was really angry not like aggressive or nothing, but just annoyed that no one listens. And it just got to stage that you're going to have to retrain your brain. They are not going to listen to you and you just gotta take this injection and make the most of what life you've got. It's not much of a life but you've got to make the most of it." (Int12)

Questions of trust surfaced in several interviews. Those with a history of coercive relationships with services, or who were taking medication by depot injection often reported a sense of mutual lack of trust between them and service providers. Some participants talked about the difficulties of forming relationships with psychiatrists who were constantly changing, and the need to build trust with professionals before they could express their concerns fully:

"It's a different psychiatrist all the time ...They don't know you (inaudible) so you can't have a heart to heart kind of talk, you know what I mean.... I would prefer it if it was someone that I would see on a regular basis....Trust, yea, friendship, it's not friendship as such but rapport, you know. You can't build a rapport once, or once now and then, you know. You need to see someone bang on regularly for them, well personally for me, to open up to, air me dirty laundry in front of them." (Int16) 
There were some accounts of positive interactions and relationships with practitioners regarding medication management, expressed by a minority of the willing and resigned accepters groups. These people felt the psychiatrist took their concerns about adverse effects and physical health more seriously, and that this was reflected in how decisions were made. In response to a specific interview question about who initiated discussions about changes to medication during psychiatric consultations, a few participants said they felt able to initiate these, either directly or via a social worker. However, reflecting the passivity and sense of powerlessness described above, others waited for professionals to suggest changes to the dose or type of medication, even though they said in interviews that they were not happy and would like a change.

\section{$\underline{\text { Discussion }}$}

Participants in our study reported long and complex histories of medication and service use, with profiles that are broadly typical of long-term users of community mental health services in the U.K (Mahadun \& Marshall, 2008). This patient group constitutes a large proportion of mental health service users, whose views and experiences are disproportionately underresearched.

Participants valued antipsychotics for reducing symptoms and risk of relapse, but difficult or unpleasant effects were near universal, including a debilitating state of lethargy and demotivation, and other physical and cognitive effects. These findings are consistent with other research involving antipsychotic users (Barbui et al., 2005, Bjornestad et al., 2017, Bulow et al., 2016, Carrick et al., 2004, Gray \& Deane, 2016, Moncrieff et al., 2009, Rogers et al., 1998). 
Overall, weighing up the positive and negative effects of medication, and the potential consequences of not taking it, most of our sample considered medication to be "the least worst option" and took medication with various levels of "willing" or "resigned" acceptance. However, even those we classified as "willing accepters" described the burden of living with adverse effects, and expressed a desire to be medication free in the future. A minority were "non-accepters", some of whom felt formally or informally forced to take medication, and were in oppositional relationships with services.

Although only two people were subject to legal restrictions (CTOs), feelings of powerlessness and lack of choice were common, and many described pressure to take medication from other people. For many, this sense of obligation had also been internalised in the form of (willing, reluctant or resigned) acceptance of medication taking. These factors may explain why only a few participants admitted to modifying their medication intake, in contrast to other research suggesting high levels of non-adherence (Bulow et al., 2016, Cooper et al., 2007), but the finding reflects another recent study with a similar population (Priebe et al., 2013). Even in the absence of legal restrictions, it seems an awareness of the potential for coercion colours many people's relationships with mental health treatment and services, a situation that has changed little over the last 15-20 years (Rogers et al., 1998, Usher, 2001).

A similar flavour or powerlessness characterised participants' accounts of reviewing medication with professionals. Although some described positive experiences, many felt there was little opportunity for their concerns (about side effects or long-term use of antipsychotics) to be acknowledged or discussed. Their accounts suggest psychiatrists often limit the agenda to current symptom management, with less attention paid to side effects and the impact of these on well-being and functioning. Many of our respondents did not feel it was possible or their place to disrupt the expected script of the consultation and some 
reported difficulties in establishing trusting relationships with a series of different psychiatrists.

A greater role in agenda-setting would accord service users more equality in decisionmaking. Positive impacts of an intervention to encourage this have been reported (Priebe et al., 2007). Strategies for enhancing shared decision-making in relation to antipsychotic medication may need to include practitioner training, patient empowerment and attention to the requirements of a genuinely therapeutic relationship in order to overcome powerful interactional inequalities, and the impacts, for some, of histories of difficult, mistrustful or coercive relationships with services (Morant et al., 2015). Enabling broader discussions that explore service users' experiences of antipsychotics, and their long-term preferences and goals, key components of genuine shared decision-making; (Charles et al., 1997), are consistent with broader cultural shifts towards mental health services that aim to promote recovery, patient-centred care and self-management.

Limitations of the current research include that the sample consisted principally of long-term service users. Results are therefore not necessarily generalizable to people with less protracted forms of mental ill-health. The purposive sampling technique means the distribution of categories of acceptance should not be taken as representative of all antipsychotic users. The sampling strategy was designed to allow us to hear the voices of those whose experiences may be hard to access, such as those with negative attitudes to services and medication. Interviewers' post-interview reflections and the depth of data suggested they were successful in establishing openness and rapport, but respondents may still have failed to report instances of non-compliance and adjustments to medication regimes. 
In conclusion, the current study provided an in depth exploration of service users' views of their involvement in decision-making about antipsychotic medication. As well as revealing the impacts of taking antipsychotics, it highlights how experiences of medication decisionmaking are characterised for many by passivity, perceived limitations of choice, low levels of involvement, and a sense of powerlessness. These factors must be addressed if we are to successfully move away from paternalistic and coercive forms of mental health care in the future. 


\section{Acknowledgements:}

Funding was provided by the National Institute for Health Research. Views expressed are those of the authors and do not necessarily represent those of the NHS, the NIHR or the Department of Health. We wish to thank members of SE-SURG, particularly the organizer Lyn Kent, and our participants. 
Table 1: Demographic and medication use characteristics of interview respondents.

\begin{tabular}{|c|c|c|}
\hline & & $\mathrm{N}(\%)$ \\
\hline Age & $\begin{array}{l}\text { Mean }=40.3 \text { years; } s . d=11.07(\text { range } \\
\text { 22-62) }\end{array}$ & \\
\hline Gender & $\begin{array}{l}\text { Male } \\
\text { Female }\end{array}$ & $\begin{array}{l}13(65 \%) \\
7(35 \%)\end{array}$ \\
\hline Ethnicity & $\begin{array}{l}\text { White British } \\
\text { Asian } \\
\text { Afro Caribbean }\end{array}$ & $\begin{array}{l}15(75 \%) \\
4(20 \%) \\
1(5 \%)\end{array}$ \\
\hline Referral service & $\begin{array}{l}\text { Generic mental health service } \\
\text { Early Intervention in Psychosis } \\
\text { Service }\end{array}$ & $\begin{array}{l}17(85 \%) \\
3(15 \%)\end{array}$ \\
\hline $\begin{array}{l}\text { Number of } \\
\text { antipsychotics } \\
\text { prescribed }\end{array}$ & $\begin{array}{l}\text { One } \\
\text { Two }\end{array}$ & $\begin{array}{l}14(70 \%) \\
6(30 \%)\end{array}$ \\
\hline $\begin{array}{l}\text { Method of } \\
\text { antipsychotic } \\
\text { delivery }\end{array}$ & $\begin{array}{l}\text { Depot intramuscular injection } \\
\text { Oral tablets } \\
\text { 'Depot' \& oral preparations }\end{array}$ & $\begin{array}{l}7(35 \%) \\
8(40 \%) \\
5(25 \%)\end{array}$ \\
\hline $\begin{array}{l}\text { Current } \\
\text { antipsychotic } \\
\text { medication }\end{array}$ & $\begin{array}{l}\text { First generation antipsychotics } \\
\text { Second generation antipsychotics } \\
\text { First and second generation } \\
\text { antipsychotics }\end{array}$ & $\begin{array}{l}12(60 \%) \\
5(25 \%) \\
3(15 \%)\end{array}$ \\
\hline
\end{tabular}




\begin{tabular}{l|l|l} 
Duration taking & $0-12$ months & $4(20 \%)$ \\
antipsychotic & $1-5$ years & $2(10 \%)$ \\
medication & 5-10years & $4(20 \%)$ \\
\hline Other medication & Including antidepressants, & $10(50 \%)$ \\
\hline for mental health & anticonvulsants and sleeping tablets & $6(30 \%)$ \\
\hline problems & &
\end{tabular}


References

Agrest, M., Barruti, S., Gabriel, R., Zalazar, V., Wikinski, S., \& Ardila-Gomez, S. (2017). Day hospital treatment for people with severe mental illness according to users' perspectives: what helps and what hinders recovery? J. Ment. Health 1-7, doi:10.1080/09638237.2016.1276526 [doi].

Angermeyer, M. C., Loffler, W., Muller, P., Schulze, B., \& Priebe, S. (2001). Patients' and relatives' assessment of clozapine treatment. Psychol. Med. 31, 509-517.

Barbui, C., Nose, M., Bindman, J., Schene, A., Becker, T., Mazzi, M. A., Kikkert, M., Camara, J., Born, A., \& Tansella, M. (2005). Sex differences in the subjective tolerability of antipsychotic drugs. J. Clin. Psychopharmacol. 25, 521-526.

Barry, C. A., Britten, N., Barber, N., Bradley, C., \& Stevenson, F. (1999). Using reflexivity to optimize teamwork in qualitative research. Qual. Health Res. 9, 26-44.

Bebbington, P. E., Angermeyer, M., Azorin, J. M., Marwaha, S., Marteau, F., \& Toumi, M. (2009). Side-effects of antipsychotic medication and health-related quality of life in schizophrenia. Acta Psychiatr. Scand. Suppl 22-28, doi:ACP1310 [pii];10.1111/j.1600-0447.2008.01310.x [doi].

Bjornestad, J., Davidson, L., Joa, I., Larsen, T. K., Hegelstad, W. t. V., Langeveld, J., Veseth, M., Melle, I., Johannessen, J. O., \& Bronnick, K. (2017). Antipsychotic treatment: experiences of fully recovered service users. Journal of Mental Health 1-7.

Braun, V. \& Clark, V. (2006). Using thematic analysis in psychology. Qualitative Research in Psychology 3, 77-101.

Bulow, P., Andersson, G., Denhov, A., \& Topor, A. (2016). Experience of Psychotropic Medication -An Interview Study of Persons with Psychosis. Issues Ment. Health Nurs. 37, 820-828, doi:10.1080/01612840.2016.1224283 [doi].

Carrick, R., Mitchell, A., Powell, R. A., \& Lloyd, K. (2004). The quest for well-being: a qualitative study of the experience of taking antipsychotic medication. Psychol. Psychother. 77, 19-33, doi:10.1348/147608304322874236 [doi].

Charles, C., Gafni, A., \& Whelan, T. (1997). Shared decision-making in the medical encounter: what does it mean? (or it takes at least two to tango). Soc. Sci. Med. 44, 681-692, doi:S0277953696002213 [pii].

Cooper, C., Bebbington, P., King, M., Brugha, T., Meltzer, H., Bhugra, D., \& Jenkins, R. (2007). Why people do not take their psychotropic drugs as prescribed: results of the 2000 National Psychiatric Morbidity Survey. Acta Psychiatr. Scand. 116, 47-53, doi:ACP974 [pii];10.1111/j.1600-

0447.2006.00974.x [doi].

Donovan, J. L. \& Blake, D. R. (1992). Patient non-compliance: deviance or reasoned decision-making? Soc. Sci. Med. 34, 507-513.

Ejaredar, M. \& Hagen, B. (2014). I was told it restarts your brain: knowledge, power, and women's experiences of ECT. J. Ment. Health 23, 31-37, doi:10.3109/09638237.2013.841870 [doi]. 
Finn, S. E., Bailey, J. M., Schultz, R. T., \& Faber, R. (1990). Subjective utility ratings of neuroleptics in treating schizophrenia. Psychol. Med. 20, 843-848.

Gillard, S., Simons, L., Turner, K., Lucock, M., \& Edwards, C. (2012). Patient and public involvement in the coproduction of knowledge: reflection on the analysis of qualitative data in a mental health study. Qual. Health Res. 22, 1126-1137, doi:1049732312448541 [pii];10.1177/1049732312448541 [doi].

Goss, C., Moretti, F., Mazzi, M. A., Del, P. L., Rimondini, M., \& Zimmermann, C. (2008). Involving patients in decisions during psychiatric consultations. Br. J. Psychiatry 193, 416-421, doi:193/5/416 [pii];10.1192/bjp.bp.107.048728 [doi].

Gray, R. \& Deane, K. (2016). What is it like to take antipsychotic medication? A qualitative study of patients with first-episode psychosis. J. Psychiatr. Ment. Health Nurs. 23, 108-115, doi:10.1111/jpm.12288 [doi].

Hofer, A., Kemmler, G., Eder, U., Edlinger, M., Hummer, M., \& Fleischhacker, W. W. (2004). Quality of life in schizophrenia: the impact of psychopathology, attitude toward medication, and side effects. J. Clin. Psychiatry 65, 932-939.

Hogman, G. \& Sandamas, G. (2000). A Question of Choice. London: Rethink Publications.

Karp, D. A. (1993). Taking anti-depressant medications: resistance, trial committment, conversion, disenchantment. Qualitative Sociology 16, 337-359.

Leucht, S., Arbter, D., Engel, R. R., Kissling, W., \& Davis, J. M. (2008). How effective are secondgeneration antipsychotic drugs? A meta-analysis of placebo-controlled trials. Mol. Psychiatry.

Leucht, S., Tardy, M., Komossa, K., Heres, S., Kissling, W., Salanti, G., \& Davis, J. M. (2012). Antipsychotic drugs versus placebo for relapse prevention in schizophrenia: a systematic review and meta-analysis. Lancet 379, 2063-2071.

Mahadun, P. N. \& Marshall, M. (2008). Insight and treatment attitude in schizophrenia: comparison of patients on depot and atypical antipsychotics. Psychiatric Bulletin 32, 53-56.

Moncrieff, J., Cohen, D., \& Mason, J. P. (2009). The subjective experience of taking antipsychotic medication: a content analysis of Internet data. Acta Psychiatr. Scand. 120, 102-111.

Morant, N., Kaminskiy, E., \& Ramon, S. (2015). Shared decision making for psychiatric medication management: beyond the micro-social. Health Expect., doi:10.1111/hex.12392 [doi].

National Institute for Health and Care Excellence (2014). Psychosis and schizophrenia in adults: treatment and management., London: NICE.

Norvoll, R. \& Pedersen, R. (2016). Exploring the views of people with mental health problems' on the concept of coercion: Towards a broader socio-ethical perspective. Soc. Sci. Med. 156, 204-211, doi:S0277-9536(16)30133-2 [pii];10.1016/j.socscimed.2016.03.033 [doi].

Olofinjana, B. \& Taylor, D. (2005). Antipsychotic drugs- information and choice; a patient survey. Psychiatric Bulletin 29, 369-371. 
Pound, P., Britten, N., Morgan, M., Yardley, L., Pope, C., Daker-White, G., \& Campbell, R. (2005). Resisting medicines: a synthesis of qualitative studies of medicine taking. Soc. Sci. Med. 61, 133-155, doi:S0277-9536(04)00606-9 [pii];10.1016/j.socscimed.2004.11.063 [doi].

Priebe, S., McCabe, R., Bullenkamp, J., Hansson, L., Lauber, C., Martinez-Leal, R., Rossler, W., Salize, H., Svensson, B., Torres-Gonzales, F., van den, B. R., Wiersma, D., \& Wright, D. J. (2007). Structured patient-clinician communication and 1-year outcome in community mental healthcare: cluster randomised controlled trial. Br. J. Psychiatry 191, 420-426.

Priebe, S., Yeeles, K., Bremner, S., Lauber, C., Eldridge, S., Ashby, D., David, A. S., O'Connell, N., Forrest, A., \& Burns, T. (2013). Effectiveness of financial incentives to improve adherence to maintenance treatment with antipsychotics: cluster randomised controlled trial. $B M J 347, \mathrm{f5847.}$

Rettenbacher, M. A., Burns, T., Kemmler, G., \& Fleischhacker, W. W. (2004). Schizophrenia: attitudes of patients and professional carers towards the illness and antipsychotic medication.

Pharmacopsychiatry 37, 103-109, doi:10.1055/s-2004-818987 [doi].

Rogers, A., Day, J. C., Williams, B., Randall, F., Wood, P., Healy, D., \& Bentall, R. P. (1998). The meaning and management of neuroleptic medication: a study of patients with a diagnosis of schizophrenia. Soc. Sci. Med. 47, 1313-1323.

Szasz, T. (1970). Ideology and Insanity; essays on the psychiatric dehumanization of man. New york: Anchor Books.

The Schizophrenia Commission (2012). The Abandoned Illness: a report from the Schizophrenia Commission. London: Rethink Mental Illness.

Usher, K. (2001). Taking neuroleptic medications as the treatment for schizophrenia: A phenomenological study. Aust. N. Z. J. Ment. Health Nurs. 10, 145-155, doi:anm205 [pii].

Venn, S. \& Arber, S. (2012). Understanding older peoples' decisions about the use of sleeping medication: issues of control and autonomy. Sociol. Health IIIn. 34, 1215-1229, doi:10.1111/j.14679566.2012.01468.x [doi].

Wunderink, L., Nieboer, R. M., Wiersma, D., Sytema, S., \& Nienhuis, F. J. (2013). Recovery in Remitted First-Episode Psychosis at 7 Years of Follow-up of an Early Dose Reduction/Discontinuation or Maintenance Treatment Strategy: Long-term Follow-up of a 2-Year Randomized Clinical Trial. JAMA Psychiatry.

Wykes, T., Evans, J., Paton, C., Barnes, T. R. E., Taylor, D., Bentall, R., Dalton, B., Ruffell, T., Rose, D., \& Vitoratou, S. (2017). What side effects are problematic for patients prescribed antipsychotic medication? The Maudsley Side Effects (MSE) measure for antipsychotic medication. Psychol. Med. 1-10, doi:S0033291717000903 [pii];10.1017/S0033291717000903 [doi].

Zhou, A. (2016). The uncertainty of treatment: Women's use of HIV treatment as prevention in Malawi. Soc. Sci. Med. 158, 52-60, doi:S0277-9536(16)30181-2

[pii];10.1016/j.socscimed.2016.04.013 [doi]. 